Preface

\title{
The Role of Fibrinogen and Factor XIII in Hemostasis, and the Identification and Treatment of Associated Disorders
}

\author{
Ton Lisman, $\mathrm{PhD}^{1}$ Philippe de Moerloose, $\mathrm{MD}^{2}$ \\ ${ }^{1}$ Section of Hepatobiliary Surgery and Liver Transplantation, \\ Department of Surgery, University of Groningen, University Medical \\ Center Groningen, Groningen, The Netherlands \\ 2 Division of Angiology and Haemostasis, University Hospitals and \\ Faculty of Medicine, Geneva, Switzerland
}

Semin Thromb Hemost 2016;42:331-332.

The thrombin-mediated conversion of fibrinogen to fibrin and the subsequent stabilization of the fibrin clot by activated FXIII are vital to adequate hemostasis. Once cross-linked, the fibrin clot is relatively resistant to fibrinolysis, ensuring longterm stability of the fibrin clot to permit repair of the damaged vessel. Indeed, qualitative or quantitative defects in either fibrinogen or FXIII may result in bleeding. ${ }^{1,2}$ Conversely, elevated fibrinogen levels are considered a risk factor for thrombotic disease, whereas FXIII may affect thrombotic risk in selected patient groups. ${ }^{3-5}$ Thus, thrombosis and hemostasis critically involve both fibrinogen and FXIII, which in turn are fascinating molecules in terms of structure and function, and clinical impact. The biochemical and biophysical properties of the fibrin clot have been partly elucidated and help us understand the mode of action of clot formation; moreover, determinants of (in)stability of the clot have been identified. ${ }^{6-8}$ FXIII is a complex molecule that exists in a different form in plasma (as a A2B2 heterotetramer) and within cells including platelets (as an A2 homodimer). Both fibrinogen and FXIII have properties beyond their well-recognized role in thrombosis and hemostasis. ${ }^{9-11}$

We are proud and pleased to present a comprehensive overview of new clinical and basic science developments in the field of fibrin formation and crosslinking. This issue of Seminars in Thrombosis \& Haemostasis starts with a provocative paper by Litvinov and Weisel who review the relevance of fibrin(ogen) for clinicians and biochemists. ${ }^{12}$ The relatively mild phenotype of the fibrinogen knockout mice has led some biochemists and clinicians to conclude that fibrinogen is not very important, but critical arguments against this conclusion are provided by Litvinov and Weisel. Subsequently, Macrae and coworkers present an update of biochemical and clinical studies on the fibrinogen gamma prime splice variant, ${ }^{13}$ which has biophysical and biochemical features that are

Address for correspondence Ton Issue Theme The Role of Lisman, PhD, Surgical Research Laboratory, BA 44, University Medical Center Groningen, Hanzeplein 1, 9713 GZ Groningen, The Netherlands (e-mail: j.a.lisman@umcg.nl).
Hemostasis, and the Identification Disorders; Guest Editors: Ton Lisman, PhD, and Philippe de Moerloose, MD. and Treatment of Associated

markedly distinct from "normal" fibrinogen, and appears associated with thrombotic disease. Besides the fibrinogen gamma prime variant, which is present in all of us, rare mutations in fibrinogen leading to decreased plasma levels, decreased fibrinogen function, or both, can occur and are associated with both a bleeding tendency and thrombotic complications. Neerman-Arbez and coworkers provide a comprehensive description of the screening for, and molecular characterization of, congenital fibrinogen abnormalities, and provide an update on the mutations that have so far been identified. ${ }^{14}$ Casini and colleagues then discuss therapeutic options in patients with congenital fibrinogen abnormalities and highlight difficult situations, including obstetric management and treatment of thrombotic events. ${ }^{15}$

The use of fibrinogen concentrate to treat acquired fibrinogen deficiencies, such as encountered in massive bleeding due to trauma, surgery, or due to postpartum bleeding, has gained popularity over the past decade. Samama argues against the liberal use of fibrinogen concentrates in massively bleeding patients and calls for additional studies to clarify the role of fibrinogen concentrates in this setting. ${ }^{16}$ Subsequently, Undas provides in-depth information on commonly used laboratory tests to assess fibrin clot properties in both routine diagnostics and research settings. ${ }^{17}$ Fibrinogen is synthesized in the liver, and patients with liver diseases may acquire quantitative and qualitative defects in fibrinogen. The consequences of these changes are discussed by Lisman and Ariëns, who provide evidence of qualitative improvements in fibrin structure in these patients despite quantitative defects. ${ }^{18}$ Alterations in fibrin(ogen) may contribute to thrombotic events that may occur in patients with liver diseases. In addition, fibrin(ogen) may play a role in the pathogenesis of liver diseases. Evidence from experimental animal models linking fibrin(ogen) to disease pathology is

Copyright (๑) 2016 by Thieme Medical Publishers, Inc., 333 Seventh Avenue, New York, NY 10001, USA. Tel: +1(212) 584-4662.
DOI http://dx.doi.org/ 10.1055/s-0036-1579656. ISSN 0094-6176. 
discussed by Kopec and Luyendyk. ${ }^{19}$ Another extrahemostatic function of fibrinogen is dealt with by Ko and Flick who discuss the central role of fibrinogen in host defense or pathogen virulence in Staphylococcus aureus infection. ${ }^{20}$

The section on FXIII of this issue of Seminars in Thrombosis $\mathcal{E}$ Haemostasis starts with a paper by Schroeder and Kohler, which deals with an update on structural features of the plasma FXIII heterotetramer and the cellular FXIII homodimer. ${ }^{21}$ In addition, the authors outline the various functions of FXIII beyond its well-recognized function as a fibrin stabilizer. Subsequently, Muszbek and Katona outline diagnosis and treatment of congenital and acquired FXIII deficiencies and highlight issues with FXIII assays and novel developments regarding allo- and autoantibodies directed to FXIII. ${ }^{22}$ Next, practical guidelines for the use of FXIII concentrates in congenital and acquired FXIII deficiency are given by Lassila. ${ }^{23}$ Finally, Byrnes and Wolberg review established and recently recognized actions of FXIII toward the fibrin clot, which include effects on fibrin structure and stability, fibrin contraction, and mechanical stability, as well as the role of FXIII in red cell retention in growing thrombi. ${ }^{24}$ In addition, epidemiological and experimental evidence for a role of FXIII in venous and arterial thrombosis is discussed.

We hope that readers of Seminars in Thrombosis \& Haemostasis enjoy this comprehensive overview of recent developments in this field and trust this compilation will inspire many to perform additional experimental or clinical work to fill in knowledge gaps that have been identified by the contributing authors.

\section{References}

1 de Moerloose P, Neerman-Arbez M. Congenital fibrinogen disorders: an update. Semin Thromb Hemost 2013;39(6):585-595

2 Karimi M, Bereczky Z, Cohan N, Muszbek L. Factor XIII deficiency. Semin Thromb Hemost 2009;35(4):426-438

3 van Hylckama Vlieg A, Rosendaal FR. High levels of fibrinogen are associated with the risk of deep venous thrombosis mainly in the elderly. J Thromb Haemost 2003;1(12):2677-2678

4 Danesh J, Lewington S, Thompson SG, et al; Fibrinogen Studies Collaboration. Plasma fibrinogen level and the risk of major cardiovascular diseases and nonvascular mortality: an individual participant meta-analysis. JAMA 2005;294(14):1799-1809
5 Bagoly Z, Koncz Z, Hársfalvi J, Muszbek L. Factor XIII, clot structure, thrombosis. Thromb Res 2012;129(3):382-387

6 Weisel JW, Litvinov RI. Mechanisms of fibrin polymerization and clinical implications. Blood 2013;121(10):1712-1719

7 Weisel JW. Structure of fibrin: impact on clot stability. J Thromb Haemost 2007;5(Suppl 1):116-124

8 Undas A, Ariëns RA. Fibrin clot structure and function: a role in the pathophysiology of arterial and venous thromboembolic diseases. Arterioscler Thromb Vasc Biol 2011;31(12):e88-e99

9 Hoppe B. Fibrinogen and factor XIII at the intersection of coagulation, fibrinolysis and inflammation. Thromb Haemost 2014; 112(4):649-658

10 Schroeder V, Kohler HP. New developments in the area of factor XIII. J Thromb Haemost 2013;11(2):234-244

11 Muszbek L, Bereczky Z, Bagoly Z, Komáromi I, Katona É. Factor XIII: a coagulation factor with multiple plasmatic and cellular functions. Physiol Rev 2011;91(3):931-972

12 Litvinov RI, Weisel JW. What is the biological and clinical relevance of fibrin? Semin Thromb Hemost 2016;42(4):333-343

13 Macrae FL, Domingues MM, Casini A, Ariëns RAS. The (patho) physiology of fibrinogen $\gamma$ '. Semin Thromb Hemost 2016;42(4): 344-355

14 Neerman-Arbez M, de Moerloose P, Casini A. Laboratory and genetic investigation of mutations accounting for congenital fibrinogen disorders. Semin Thromb Hemost 2016;42(4):356-365

15 Casini A, de Moerloose P, Neerman-Arbez M. Clinical features and management of congenital fibrinogen deficiencies. Semin Thromb Hemost 2016;42(4):366-374

16 Samama CM. Fibrinogen concentrates for acquired fibrinogen deficiencies? Semin Thromb Hemost 2016;42(4):375-380

17 Undas A. How to assess fibrinogen levels and fibrin clot properties in clinical practice? Semin Thromb Hemost 2016;42(4):381-388

18 Lisman T, Ariëns RAS. Alterations in fibrin structure in patients with liver diseases. Semin Thromb Hemost 2016;42(4):389-396

19 Kopec AK, Luyendyk JP. Role of fibrin(ogen) in progression of liver disease: guilt by association? Semin Thromb Hemost 2016;42(4): 397-407

20 Ko Y-P, Flick MJ. Fibrinogen is at the interface of host defense and pathogen virulence in Staphylococcus aureus infection. Semin Thromb Hemost 2016;42(4):408-421

21 Schroeder V, Kohler HP. Factor XIII: structure and function. Semin Thromb Hemost 2016;42(4):422-428

22 Muszbek L, Katona E. Diagnosis and management of congenital and acquired FXIII deficiencies. Semin Thromb Hemost 2016; 42(4):429-439

23 Lassila R. Clinical use of factor XIII concentrates. Semin Thromb Hemost 2016;42(4):440-444

24 Byrnes JR, Wolberg AS. Newly-recognized roles of factor XIII in thrombosis. Semin Thromb Hemost 2016;42(4):445-454 